\title{
Novel genetic environment of the plasmid-mediated KPC-3 gene detected in Escherichia coli and Citrobacter freundii isolates from China
}

\author{
G. Li $\cdot$ Q. Wei $\cdot$ Y. Wang $\cdot$ X. Du $\cdot$ Y. Zhao $\cdot$ X. Jiang
}

Received: 1 September 2010 /Accepted: 20 November 2010 /Published online: 14 December 2010

(C) The Author(s) 2010. This article is published with open access at Springerlink.com

\begin{abstract}
The imipenem and meropenem-resistant strains Citrobacter freundii HS70 and Escherichia coli HS510 were isolated from patients in Shanghai, China. By isoelectric focusing, PCR amplification and sequencing, these strains were each found to produce four $\beta$-lactamases: TEM-1, KPC-3, SHV-7 and CTX-M-14. A conjugation experiment and plasmid restriction digestion revealed that the $b l a_{\mathrm{KPC}-3}$ gene was located on the same plasmid in both isolates. Bidirectional primer walking sequencing showed that the nucleotide sequence surrounding the $3.8 \mathrm{~kb} b l a_{\mathrm{KPC}-3}$ contained a 671-bp insertion similar to that previously characterized in China. The insertion was located between the promoter and the coding region of the $b l a_{\mathrm{KPC}-3}$ gene. Susceptibility testing performed on recombinant strains carrying the $b l a_{\mathrm{KPC}-3}$ gene with or without the insertion revealed that minimum inhibitory concentrations of imipenem, meropenem, cefepime, and cefotaxime for E. coli EMU-KPC3 (without insertion) were four times higher than that of E. coli EKPC3 (with insertion). The 671 bp insertion reduced $b l a_{\mathrm{KPC}-3}$ expression significantly. Taken together, these results suggest that KPC-3-producing $C$. freundii and E. coli have begun to emerge in our hospital.
\end{abstract}

G. Li $\cdot$ Q. Wei $\cdot$ Y. Wang $\cdot$ X. Du $\cdot$ X. Jiang $(\bowtie)$

Department of Laboratory Medicine, Huashan Hospital,

Shanghai Medical College, Fudan University,

12 Central Urumqi Road,

Shanghai, China

e-mail: jiangxi2154@yahoo.com.cn

G. Li $\cdot$ Y. Zhao

Department of Laboratory Medicine, Jinshan Hospital,

Shanghai Medical College, Fudan University,

391 East Jinyi Road,

Shanghai, China

\section{Introduction}

The extensive use of carbapenems has resulted in the emergence of carbapenem-resistant Enterobacteriaceae strains [4]. The resistance may be mediated by the production of carbapenemases [15, 19], as well as AmpC hyper-production combined with decreased outer membrane permeability due to loss or alteration of porins [14]. The Ambler class A Klebsiella pneumoniae carbapenemase (KPC) enzymes [13] are able to hydrolyze all known $\beta$ lactam-containing molecules and are the most frequently observed class A carbapenemases.

KPC-1, a plasmid encoded $\beta$-lactamase, was first identified from $K$. pneumoniae in North Carolina (USA) and is identical to the $b l a_{\mathrm{KPC}-2}$ gene by sequencing $[25,26]$. Strains harboring $b l a_{\mathrm{KPC}-1 / \mathrm{KPC}-2}$ have also been isolated from patients in France [9], Israel [12], South America [18], Greece [3], and China [20]. The bla $a_{\mathrm{KPC}-3}$ sequence (GenBank AM774409) is found in the same genetic environment as bla $a_{\mathrm{KPC}-2}$ in Salmonella cubana 4707 (GenBank AF481906) [5], and this KPC enzyme is now prevalent in America [22], Israel [6], and the United Kingdom [23].

In this study, we identified strains of Citrobacter freundii and $E$. coli isolated from Chinese patients that express KPC-3. The background of the $b l a_{\mathrm{KPC}-3}$ gene was different from that reported outside of China and it was similar to that reported in China previously [27].

\section{Materials and methods \\ Bacterial strains and plasmids}

The imipenem and meropenem-resistant strain $C$. freundii HS70 was isolated from the urine of a 53-year-old female 
patient hospitalized in Huashan Hospital, Fudan University. The imipenem and meropenem-resistant strain E. coli HS510 was isolated from urine of a 59-year-old female inpatient at the same hospital. Both strains were identified by Vitek-32 (BioMerieux, Marcy, France). E. coli J53 was used as a recipient in conjugal mating experiments, whereas $E$. coli $\mathrm{DH} 5 \alpha$ was used for cloning. Other derivative strains and plasmids used in this study are listed in Table 1.

\section{Antimicrobial susceptibility testing}

Minimum inhibitory concentrations (MICs) for organisms were determined by the Mueller-Hinton $(\mathrm{M}-\mathrm{H})$ agar dilution method according to guidelines of the Clinical and Laboratory Standards Institute [2]. Antimicrobial agents evaluated included imipenem, meropenem, cefepime, cefotaxime, ampicillin, ciprofloxacin, and gentamicin. All were obtained from Oxoid (Basingstoke, England). E. coli ATCC25922 was used for quality control.

Conjugation experiments and plasmid restriction enzyme digestion analysis

Transfer of imipenem resistance was studied by performing conjugation experiments as previously described [24] with $E$. coli $\mathrm{J} 53$ as the recipient. Transconjugants were selected from agar plates supplemented with sodium azide $(100 \mu \mathrm{g} / \mathrm{mL}$; Oxoid, Basingstoke, England) and ceftazidime $(2 \mu \mathrm{g} / \mathrm{mL}$; Oxoid, Basingstoke, England), and identified by VITEK-32. For the plasmid restriction enzyme analysis, $\mathrm{XbaI}$ and $\mathrm{ClaI}$
(Takara, Dalian, China) were used. Digested plasmid DNA samples from transconjugants were then analyzed by electrophoresis on $0.6 \%$ agarose gels at a constant voltage of $100 \mathrm{~V}$ for $0.5 \mathrm{~h}$.

Isoelectric focusing of $\beta$-lactamases

Crude cell lysates were prepared by a previously described freeze-thaw procedure [17]. Isoelectric focusing was performed as described by Matthew and Harris [8]. Cell extracts were loaded onto prepared polyacrylamide gel plates ( $\mathrm{pH} 3$ to 9; Amersham Biosciences, Uppsala, Sweden) and electrophoresed to equilibrium using Pharmacia PhastSystem (Uppsala, Sweden). $\beta$-lactamases were then visualized by staining the gel with a $0.05 \%$ solution of nitrocefin (BD Biosciences, San Jose, CA, USA). The isoelectric points of TEM-1, KPC-3, SHV-7 and CTX-M14 were determined by comparison to known pIs of the $\beta$ lactamases (TEM-12, pI 5.25; TEM-28, pI 6.1; SHV-7, pI 7.6; and ACT-1, pI 9.0).

PCR analysis and nucleotide sequencing

Crude genomic DNA was extracted from the isolates by heat lysis. $\beta$-lactamase genes were identified by PCR with specific primers designed to sequences of known $\beta$-lactamase genes, including $b l a_{\mathrm{TEM}}, b l a_{\mathrm{SHV}}, b l a_{\mathrm{KPC}}, b l a_{\mathrm{CTX}-\mathrm{M}-1}, b l a_{\mathrm{CTX}-\mathrm{M}-9 \text {, }}$ and $b_{l a} a_{\mathrm{CTX}-\mathrm{M}-2}$. For PCRs the LA Taq DNA polymerase (Takara, Dalian, China) was used according to the manufacturer's instructions. Primer sequences are listed in Table 2.
Table 1 Bacterial strains and plasmids used in this study

\begin{tabular}{lll}
\hline Strains or plasmids & Description & Reference \\
\hline Plasmids & & \\
pACYC184 & Cloning vector & \\
pacyc184-KPC3 & Insertion of 727-2902 region between BamH I & FJ609231 \\
and EcoRI restriction site in pACYC184 & FJ609231 \\
pMU-acyc184-KPC3 & Deletion of 1188-1706 in pacyc184-KPC3 & This study \\
pHS70 & Plasmid from E. coli J 53 (pHS70) & This study \\
pHS510 & Plasmid from E. coli J 53 (PhS510) & \\
Strains & & This study \\
Citrobacter freundii & & \\
HS70 & Clinical isolate & This study \\
E. coli & & This study \\
HS510 & Clinical isolate & This study \\
E. coli J 53 (pHS70) & E. coli J53 transconjugant derived from HS70 & This study \\
E. coli J 53 (pHS510) & E. coli J53 transconjugant derived from HS510 & This study \\
EKPC3 & E. coli DH5a containing pacyc184-KPC3 & \\
EMU-KPC3 & E. coli DH5a containing pMU-acyc184-KPC3 & \\
DH5 $\alpha$ & E. coli reference lab strain & \\
J53 & E. coli reference lab strain & \\
ATCC25922 & E. coli reference lab strain & \\
\hline
\end{tabular}


Table 2 Primers for PCR amplification of the $\beta$-lactamases genes and for cloning

\begin{tabular}{|c|c|c|c|c|}
\hline ESBL or plasmid & Primer & Sequence & Position & $\begin{array}{l}\text { GenBank accession } \\
\text { number or reference }\end{array}$ \\
\hline \multirow[t]{2}{*}{ KPC } & KPC-F & 5'-ATGTCACTGTATCGCCGTCT-3' & $131-150$ & \multirow[t]{2}{*}{ AF297554 } \\
\hline & KPC-R & 5'-TTTTCAGAGCCTTACTGCCC-3' & $1023-1042$ & \\
\hline \multirow[t]{2}{*}{ TEM } & TEM-F & 5'-ATAAAATTCTTGAAGAC-3' & $1-17$ & \multirow[t]{2}{*}{ X54604.1 } \\
\hline & TEM-R & 5'-TTACCAATGCTTAATCA-3' & $1075-1059$ & \\
\hline \multirow[t]{2}{*}{ SHV } & SHV-F & 5'-TGGTTATGCGTTATATTCGCC-3 & $69-89$ & \multirow[t]{2}{*}{ X98100.1 } \\
\hline & SHV-R & 5'-GCTTAGCGTTGCCAGTGCT-3' & $936-918$ & \\
\hline \multirow[t]{2}{*}{ CTX-M-1 } & $\mathrm{M} 1 \mathrm{~F}$ & 5'- GGTTAAAAAATCACTGCGTC -3 & $65-84$ & \multirow[t]{2}{*}{ X92506 } \\
\hline & M1 R & 5'- TTGGTGACGATTTTAGCCGC-3 & $928-909$ & \\
\hline \multirow[t]{3}{*}{ CTX-M-9 } & M9F & 5'-ATGGTGACAAAGAGAGTGCA-3 & $1-20$ & \multirow[t]{3}{*}{ AF252621.2 } \\
\hline & M9R & 5'-CCCTTCGGCGATGATTCTC-3' & $870-852$ & \\
\hline & $\mathrm{M} 2 \mathrm{~F}$ & 5'-ATGATGACTCAGAGCATTCG-3' & $304-323$ & \\
\hline CTX-M-2 & $\mathrm{M} 2 \mathrm{R}$ & 5'-TGGGTTACGATTTTCGCCGC-3' & $1169-1150$ & AJ416343.1 \\
\hline \multirow[t]{2}{*}{ pacyc184-KPC3 } & KPC-3 F & 5'-GCCTGGTCCGAATTCCCTCGTCATCCGCAGACCAAC-3' & $727-747$ & \multirow[t]{2}{*}{ FJ609231 } \\
\hline & KPC-3R & 5'-GCCTGGTCCGGATCCCGCGCAGACTCCTAGCCTAAA-3' & $2882-2902$ & \\
\hline \multirow[t]{2}{*}{ pMU-acyc184-KPC3 } & MU-KPC-3 F & 5'-CTTAACGTGAGTTTTCGTTCCACTGAGCG-3' & $1816-1844$ & \multirow[t]{2}{*}{ FJ609231 } \\
\hline & MU-KPC-3R & 5'-AAGTCATTTTTCAATATTATTGAAGCATTT ATC-3' & $1112-1144$ & \\
\hline
\end{tabular}

ESBL extended-spectrum beta-lactamase

PCR amplifications were performed and PCR products were then sequenced by an ABI 3730 analyzer, and the obtained sequences were aligned with sequence data from GenBank.

Analysis of the genetic environment of the blaKPC-3 gene and plasmid construction

The genetic context of the $b l a_{\mathrm{KPC}-3}$ gene was examined by bidirectional primer walking sequencing, performed on plasmids from transconjugants using primers designed previously [20]. The obtained sequence was aligned with $\beta$-lactamase sequences from the GenBank database using the BLAST program. Primers KPC-3 F and KPC-3R were used to amplify the DNA fragments, which included the entire $b l a_{\mathrm{KPC}}$ gene and the region flanking the insertion in the plasmid isolated from the Chinese patients. The obtained PCR products and plasmid pACYC184 were digested using Bam $\mathrm{HI}$ and EcoRI, then ligated using T4 DNA ligase. The obtained plasmid pACYC184-KPC3 was electroporated into E. coli $\mathrm{DH} 5 \alpha$. Clones were selected on Luria-Bertani agar plates containing chloramphenicol $(40 \mathrm{mg} / \mathrm{mL})$ and imipenem $(1.5 \mathrm{mg} / \mathrm{mL})$. Primers MUKPC-3F and MU-KPC-3R were designed to amplify the whole recombinant plasmid pACYC184-KPC3 without the $671 \mathrm{bp}$ insertion fragment. The obtained PCR products were ligated by using a MutantBEST kit (Takara) to produce the plasmid pMU-ACYC184-KPC3. The recombinant plasmids pACYC184-KPC3 (with insertion) and pMU-ACYC184-KPC3 (without insertion) were then indi- vidually transformed into E. coli $\mathrm{DH} 5 \alpha$ by the calcium phosphate method.

\section{Results}

Antimicrobial resistance

E. coli HS510 was isolated from the urine of a 59-year-old female patient and was found resistant to imipenem and meropenem, with a MIC of $16 \mu \mathrm{g} / \mathrm{mL}$ for both antibiotics. C. freundii HS70 was isolated from the urine of a 53-yearold female patient and had a MIC of $\geq 128 \mu \mathrm{g} / \mathrm{mL}$ for both antibiotics (Table 3).

Isoelectric focusing and PCR analysis of $\beta$-lactamases

In order to understand the antimicrobial resistant phenotype, $\beta$-lactamases were analyzed by isoelectric focusing, PCR and PCR product sequencing. Isoelectric focusing of clinical isolates revealed that both E. coli HS510 and $C$. freundii HS70 produced four $\beta$-lactamases which possess pIs of 5.4, 6.7, 7.6, and 8.1 (Fig. 1), respectively. To determine which lactamases they were, PCR was performed on DNA from the clinical isolates with primers specific for KPC, TEM, SHV, CTX-M-1, CTX-M-2, and CTX-M-9. Sequencing analysis of two clinical isolates confirmed that both E. coli HS510 and $C$. freundii HS70 carried bla $a_{\text {TEM-1 }}$, bla $_{\mathrm{CTX}-\mathrm{M}-14}, b_{\mathrm{SHV}-7}$ and $b l a_{\mathrm{KPC}-3}$. 
Table 3 Antimicrobial susceptibility patterns ${ }^{\mathrm{a}}$

\begin{tabular}{|c|c|c|c|c|c|c|c|}
\hline \multirow[t]{2}{*}{ Antimicrobial agent(s) } & \multicolumn{7}{|c|}{$\mathrm{MIC}(\mu \mathrm{g} / \mathrm{mL})$} \\
\hline & $\mathrm{HS}^{\circ}{ }^{\mathrm{b}}$ & E. coli $\mathrm{J} 53(\mathrm{pHS} 70)$ & HS510 & E. coli $\mathrm{J} 53(\mathrm{pHS} 510)$ & EKPC3 & EMU-KPC3 & $25922^{\mathrm{c}}$ \\
\hline Imipenem & $\geq 128$ & 2 & 16 & 2 & 8 & 32 & $\leq 0.0625$ \\
\hline Meropenem & $\geq 128$ & 2 & 16 & 2 & 8 & 32 & $\leq 0.0625$ \\
\hline Cefepime & $\geq 128$ & 8 & 64 & 8 & 16 & 64 & $\leq 0.0625$ \\
\hline Cefotaxime & $\geq 128$ & 16 & $\geq 128$ & 16 & 16 & 64 & $\leq 0.0625$ \\
\hline Ampicillin & $\geq 128$ & $\geq 128$ & $\geq 128$ & $\geq 128$ & $\geq 128$ & $\geq 128$ & 2 \\
\hline Ciprofloxacin & $\geq 128$ & $\leq 0.0625$ & $\geq 128$ & $\leq 0.0625$ & $\leq 0.0625$ & $\leq 0.0625$ & $\leq 0.0625$ \\
\hline Gentamicin & $\geq 128$ & $\leq 0.0625$ & $\geq 128$ & $\leq 0.0625$ & $\leq 0.0625$ & $\leq 0.0625$ & $\leq 0.0625$ \\
\hline
\end{tabular}

${ }^{\text {a }}$ Minimum inhibitory concentrations (MICs) were determined by the M-H agar dilution method according to guidelines of the Clinical and Laboratory Standards Institute

${ }^{\mathrm{b}}$ Clinical isolates: E. coli HS510 and C. freundii HS70. Transconjugants: E. coli J 53 (pHS510); E. coli J 53 (pHS70). Recombinants: EKPC3, E. coli DH5a/ pacyc184-KPC3; EMU-KPC3, E. coli DH5a/ pMU-acyc184-KPC3. Lab reference E. coli strain: 25922

c $E$. coli ATCC 25922 was used as quality control of antimicrobial susceptibility testing

\section{Plasmid profile analysis}

Conjugation experiments successfully transferred a plasmid from both clinical isolates to the recipient $E$. coli J53. In order to understand which resistant genes can be transferred by plasmid conjugation, we used PCR to identify every $\beta$ lactamase gene that the two clinical isolates contained on transconjugants. PCR results confirmed that both transconjugants only carried the blaKPC-3 gene. Restriction enzyme (XbaI and Clal) digestion of plasmids from transconjugants showed that they had identical enzyme digestion maps (Fig. 2). Our results indicated that the $b l a_{\mathrm{KPC}}$ gene was located on the same plasmid in both clinical isolates.

Fig. 1 Isoelectric focusing patterns of clinical isolates $E$. coli HS510 and C. freundii HS70. Lane 1: Cell lysate prepared from C. freundii $\mathrm{HS} 70$ producing TEM-1 (pI 5.4), KPC-3 (pI 6.7), SHV-12 (pI 7.6), and CTX-M-14 (pI 7.9). Lane 2: Cell lysate prepared from E. coli $\mathrm{HS} 510$ producing TEM-1, KPC-3, SHV-12 and CTX-M-14

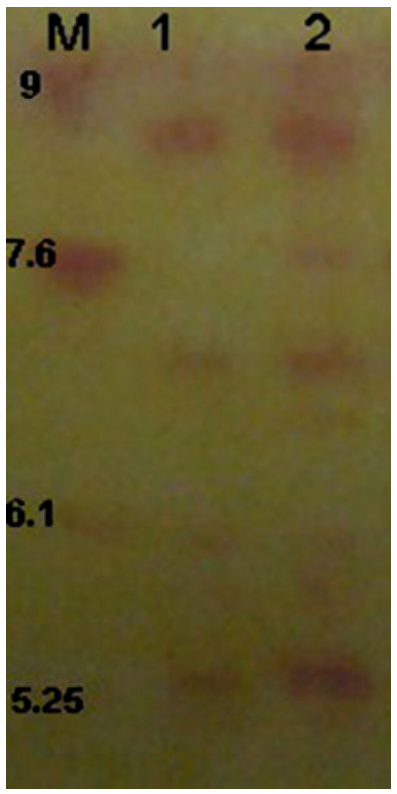

Characterization of the genetic environment of the blaKPC-3 gene

Bidirectional primer walking performed on transconjugated plasmids produced a $3,850 \mathrm{bp}$ fragment. The nucleotide

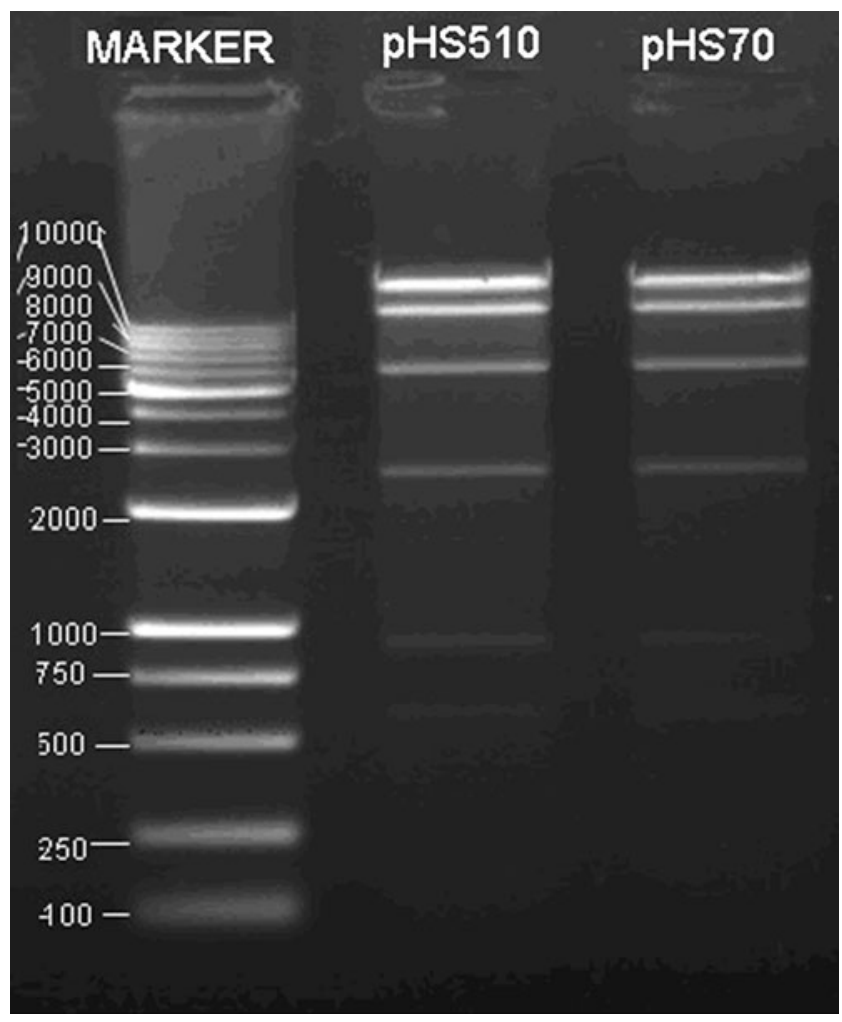

Fig. 2 Electrophoretic analysis of XbaI- and ClaI-digested plasmids. Lane 2: E. coli transconjugants of HS70. Lane 3: E. coli transconjugants of HS510. Marker lane: 100-bp and 1-Kb DNA ladders (Takara) 
sequence was assigned GenBank accession number FJ609231. Sequence alignment showed that the FJ609231 sequence was similar to AM774409.1. FJ609231 carried the $b l a_{\mathrm{KPC}-3}$ gene; EU176014.1 and FJ628167 each carried a $b l a_{\mathrm{KPC}-2}$ gene. Furthermore, FJ609231 showed a similar structure and context with FJ628167, except for a 671-bp fragment insertion between the $b l a_{\mathrm{KPC}-3}$ promoter and the $b l a_{\mathrm{KPC}}$ coding region (between positions 20571 and 20572 of FJ628167; see Fig. 3). As for FJ628167, an ISKpn6-like element is located downstream of the $b l a_{\mathrm{KPC}-3}$ gene and a Tn3 transposon and ISKpn8 is located upstream of the $b l a_{\mathrm{KPC}-3}$ gene [27]. The additional $671 \mathrm{bp}$ insertion looks like a piece of TEM1. The nucleotide sequence area is from 982 to 1928 of FJ609231, and looks like a rearranged FJ223605.1.

Antimicrobial susceptibility testing of recombinants

To investigate the effects of the inserted 671-bp fragment on bla $a_{\mathrm{KPC}-3}$ expression, plasmids pKPC3-184 and pMUKPC3-184 were constructed using the vector pACYC184. The plasmid pKPC3-184 was derived from plasmid pHS70, and pMU-KPC3-184 was derived from plasmid pKPC3184. The genetic environment of the $b l a_{\mathrm{KPC}}$ gene on pKPC3-184 was the same with pHS70. The genetic environment of the $b l a_{\mathrm{KPC}}$ gene on pMU-KPC3-184 was the same with pHS70 except for a 671-bp fragment insertion between the $b l a_{\mathrm{KPC}-3}$ promoter and the $b l a_{\mathrm{KPC}}$ coding region. Recombinants E. coli EKPC 3 and E. coli EMU-KPC3 (with plasmids pKPC3-184 and pMU-KPC3184 , respectively) were constructed and tested for antimicrobial susceptibility. The MICs of E. coli EMU-KPC3 for imipenem and meropenem were four times higher than that of $E$. coli $\mathrm{EKPC} 3(32 \mu \mathrm{g} / \mathrm{mL}$ vs. $8 \mu \mathrm{g} / \mathrm{mL})$ as were MICs for cefepime and cefotaxime $(64 \mu \mathrm{g} / \mathrm{mL}$ for $E$. coli EMU-

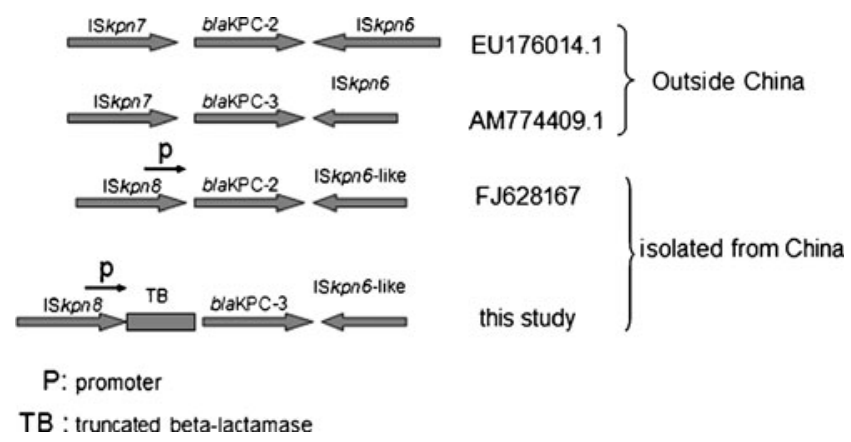

Fig. 3 Schematic representation of novel genetic structure involved in bla $_{\mathrm{KPC}-3}$ gene found in bacteria isolated from Chinese patients. EU176014.1 contains ISKpn7, bla $a_{\mathrm{KPC}-3}$ and ISKpn6; AM774409.1 contains ISKpn7, bla $a_{\mathrm{KPC}-2}$ and ISKpn6; FJ628167 contains ISKpn8, $b l a_{\mathrm{KPC}-2}$ and an ISKpn6-like element; this study contained ISKpn8, truncated $\beta$-latamase, $b l a_{\mathrm{KPC}-3}$ and an ISKpn6-like element
KPC3 vs. $16 \mu \mathrm{g} / \mathrm{mL}$ for E. coli $\mathrm{EKPC} 3)$, implying that the 671-bp fragment insertion decreased KPC-3 expression.

\section{Discussion}

This is the first time that the $b l a_{\mathrm{KPC}-3}$ gene was reported in China. Nine KPC variants have so far been described (KPC-2 to KPC-10; KPC-1 and KPC-2 are identical) in different parts of the world; variants of KPC-1/2 differ by, at most, two amino acid substitutions [1, 5, 6, 16, 21, 22]. The emergence of KPC-type carbapenem-hydrolyzing enzymes is alarming. E. coli transconjugants carrying the bla $_{\mathrm{KPC}-3}$ gene from either clinical isolate in our study had MICs of $2 \mu \mathrm{g} / \mathrm{mL}$ for both imipenem and meropenem. Additional mechanisms must underlie the drug resistance of clinical isolates $C$. freundii HS70 and E. coli HS510 since their MICs for imipenem and meropenem were greater than that of their E. coli transconjugants. Previous reports showed that the lost porins OmpK36 and OmpK35 are perhaps associated with the increase in MICs for carbapenems [22].

Our conjugation experiments, plasmid restriction enzyme digestion analysis and PCR of the $\beta$-lactamase gene confirmed that bla $_{\mathrm{KPC}-3}$ from both clinical isolates is located on the same conjugational plasmid. Sequence analysis revealed that $3.8 \mathrm{~Kb}$ of DNA sequence surrounding the $b l a_{\mathrm{KPC}-3}$ gene of these two isolates was also the same, and its construction was similar to AM774409.1 from Enterobacter cloacae and EU176014.1 from Klebsiella pneumoniae. It was composed of ISKpn8, the bla $a_{\mathrm{KPC}-3}$ promoter, a 671-bp insertion, the $b l a_{\mathrm{KPC}-3}$ gene and an ISkpn6-like element (Fig. 3). This DNA fragment is one part of a Tn3-based transposon, $\mathrm{Tn} 4401$, which is likely to be the origin of $b l a_{\mathrm{KPC}}$ mobilization and further insertion into various plasmids of non-clonally related organisms [10].

This report provides further confirmation of the putatively transposable element found on plasmids of $K$. pneumoniae and $P$. aeruginosa that may be responsible for the rapid global dissemination of this gene. The region upstream of the $b l a_{\mathrm{KPC}-3}$ identified here differs from AM774409.1 and EU176014.1 (Fig. 3). A 671-bp fragment insertion was found between the $b l a_{\mathrm{KPC}-3}$ promoter and the bla $a_{\mathrm{KPC}-3}$ coding region (between positions 20571 and 20572 of FJ628167). This finding confirms Naas's proposition [10] that this region of the element is unstable, and suggests that other isoforms of Tn4401 do exist. Naas et al. identified a 100-bp deletion upstream of $b l a_{\mathrm{KPC}}$ from two clinical strains of $K$. pneumonia, namely, GR and YC [10].

Interestingly, we found that the insertion decreased bla $_{\mathrm{KPC}-3}$ expression. Our results provide important information on the genetic environment of $b l a_{\mathrm{KPC}-3}$ genes identified in clinical isolates in China and the significance of bla $a_{\mathrm{KPC}-3}$ in this genetic context warrants further study. 
Funding The present study was supported in part by the Key Technologies Research and Development Program for Infectious Diseases of China (no. 2009ZX10004-104), the National Natural Science Foundation of China (no. 81071396), funding from the Shanghai Medical Key Discipline and the Science Foundation of Shanghai Jinshan (2008-3-5).

Open Access This article is distributed under the terms of the Creative Commons Attribution Noncommercial License which permits any noncommercial use, distribution, and reproduction in any medium, provided the original author(s) and source are credited.

\section{References}

1. Alba J, Ishii Y, Thomson K, Moland ES, Yamaguchi K (2005) Kinetics study of KPC-3, a plasmid-encoded class A carbapenemhydrolyzing $\beta$-lactamase. Antimicrob Agents Chemother 49:4760-4762

2. Clinical and Laboratory Standards Institute (2009) Methods for dilution antimicrobial susceptibility tests for bacteria that grow aerobically, 7th ed. Approved standard M7-A8, Wayne, PA, USA

3. Cuzon G, Naas T, Demachy MC, Nordmann P (2008) Plasmid-mediated carbapenem-hydrolyzing $\beta$-lactamase KPC-2 in Klebsiella pneumoniae isolate from Greece. Antimicrob Agents Chemother 52:796-797

4. Deshpande LM, Jones RN, Fritsche TR, Sader HS (2006) Occurrence and characterization of carbapenemase-producing Enterobacteriaceae: report from the SENTRY Antimicrobial Surveillance Program (2000 2004). Microb Drug Resist 12:223-230

5. Dortet L, Radu I, Gautier V, Blot F, Chachaty E, Arlet G (2008) Intercontinental travels of patients and dissemination of plasmidmediated carbapenemase KPC-3 associated with OXA-9 and TEM-1. J Antimicrob Chemother 61:455-457

6. Leavitt A, Navon-Venezia S, Chmelnitsky I, Schwaber MJ, Carmeli Y (2007) Emergence of KPC-2 and KPC-3 in carbapenem-resistant Klebsiella pneumoniae strains in an Israeli hospital. Antimicrob Agents Chemother 51:3026-3029

7. Kitchel B, Rasheed JK, Patel JB, Srinivasan A, Navon-Venezia S, Carmeli Y, Brolund A, Giske CG (2009) Molecular epidemiology of KPC-producing Klebsiella pneumoniae isolates in the United States: clonal expansion of multilocus sequence type 258 . Antimicrob Agents Chemother 53:3365-3370

8. Matthew M, Harris AM (1976) Identification of $\beta$-lactamases by analytical isoelectric focusing: correlation with bacterial taxonomy. J Gen Microbiol 94:55-67

9. Naas TP, Nordmann P, Vedel G, Poyart C (2005) Plasmid-mediated carbapenem-hydrolyzing $\beta$-Lactamase KPC in a Klebsiella pneumoniae isolate from France. Antimicrob Agents Chemother 49:4423-4424

10. Naas T, Cuzon G, Villegas MV, Lartigue MF, Quinn JP, Nordmann P (2008) Genetic structures at the origin of acquisition of the $\beta$-lactamase $b l a_{\mathrm{KPC}}$ gene. Antimicrob Agents Chemother 52:1257-1263

11. Navon-Venezia S, Leavitt AA, Schwaber MJ, Rasheed JK, Srinivasan A, Patel JB, Carmeli Y, Israeli KPC, Kpn Study Group (2009) First report on a hyperepidemic clone of KPC-3-producing Klebsiella pneumoniae in Israel genetically related to a strain causing outbreaks in the United States. Antimicrob Agents Chemother 53:818-820

12. Navon-Venezia S, Chmelnitsky I, Leavitt A, Schwaber MJ, Schwartz D, Carmeli Y (2006) Plasmid-mediated imipenem-hydrolyzing enzyme KPC-2 among multiple carbapenem-resistant Escherichia coli clones in Israel. Antimicrob Agents Chemother 50:3098-3101
13. Nordann P, Cuzon G, Naas T (2009) The real threat of Klebsiella pneumoniae carbapenemase-producing bacteria. Lancet Infect Dis 9:228-236

14. Poirel L, Heritier C, Spicq C, Nordmann P (2004) In vivo acquisition of high-level resistance to imipenem in Escherichia coli. J Clin Microbiol 42:3831-3833

15. Queenan AM, Bush K (2007) Carbapenemases: the versatile beta-lactamases. Clin Microbiol Rev 20:440-458

16. Robledo IE, Moland ES, Aquino EA, Vázquez GJ, Santé MI, Bertrán J, Hanson ND (2007) First report of a KPC-4 and CTX-M producing $K$. pneumoniae $(\mathrm{Kp})$ isolated from Puerto Rico (PR). Abstracts of the 47th Interscience Conference on Antimicrobial Agents and Chemotherapy, Chicago, IL, Washington, DC, USA. American Society for Microbiology, p 142, Abstract C2-1933

17. Sykes RB, Bonner DP, Bush K, Georgopapadakou NH (1982) Azthreonam (SQ 26, 776), a synthetic monobactam specifically active against aerobic gram-negative bacteria. Antimicrob Agents Chemother 21:85-92

18. Villegas MV, Lolans K, Correa A, Suarez CJ, Lopez JA, Vallejo M, Quinn JP, Colombian Nosocomial Resistance Study Group (2006) First detection of the plasmid-mediated class A carbapenemase KPC-2 in clinical isolates of Klebsiella pneumoniae from South America. Antimicrob Agents Chemother 50:2880-2882

19. Walsh TR (2005) The emergence and implications of metallolactamases in Gram-negative bacteria. Clin Microbiol Infect 11 (suppl 6):2-9

20. Wei ZQ, Du XX, Yu YS, Shen P, Chen YG, Li LJ (2007) Plasmidmediated KPC-2 in a Klebsiella pneumoniae isolate from China. Antimicrob Agents Chemother 51:763-765

21. Wolter DJ, Kurpiel PM, Woodford N, Palepou MF, Goering RV, Hanson ND (2009) Phenotypic and enzymatic comparative analysis between the novel KPC variant, KPC-5, and its evolutionary variants, KPC-2 and KPC-4. Antimicrob Agents Chemother 53:557-562

22. Woodford N, Tierno PM Jr, Young K, Tysall L, Palepou MF, Ward E, Painter RE, Suber DF, Shungu D, Silver LL, Inglima K, Kornblum J, Livermore DM (2004) Outbreak of Klebsiella pneumoniae producing a new carbapenem-hydrolyzing class $\mathrm{A}$ $\beta$-lactamase, KPC-3, in a New York Medical Center. Antimicrob Agents Chemother 48:4793-4799

23. Woodford N, Zhang J, Warner M, Kaufmann ME, Matos J, MacDonald A, Brudney D, Sompolinsky D, Navon-Venezia S, Livermore DM (2008) Arrival of Klebsiella pneumoniae producing $\mathrm{KPC}$ carbapenemase in the United Kingdom. J Antimicrob Chemother 62:1261-1264

24. Yan JJ, Wu SM, Tsai SH, Wu JJ, Su IJ (2000) Prevalence of SHV-12 among clinical isolates of Klebsiella pneumoniae producing extended-spectrum $\beta$-lactamases and identification of a novel AmpC enzyme (CMY-8) in Southern Taiwan. Antimicrob Agents Chemother 44:1438-1442

25. Yigit H, Queenan AM, Anderson GJ, Domenech-Sanchez A, Biddle JW, Steward CD, Alberti S, Bush K, Tenover FC (2001) Novel carbapenem-hydrolyzing $\beta$-lactamase, KPC-1, from a carbapenem-resistant strain of Klebsiella pneumoniae. Antimicrob Agents Chemother 45:1151-1161

26. Yigit H, Queenan AM, Anderson GJ, Domenech-Sanchez A, Biddle JW, Steward CD, Alberti S, Bush K, Tenover FC (2008) Novel carbapenem-hydrolyzing $\beta$-lactamase KPC-1 from a carbapenem-resistant strain of Klebsiella pneumoniae. Antimicrob Agents Chemother 52:809

27. Shen P, Wei Z, Jiang Y, Du X, Ji S, Yu Y, Li L (2009) Novel genetic environment of the carbapenem-hydrolyzing betalactamase KPC-2 among Enterobacteriaceae in China. Antimicrob Agents Chemother 53:4333-4338 